\title{
Grupo internacional de trabajo por el derecho al cuidado nutricional de los pacientes
}

\author{
International Working Group for Patients' Right to Nutritional Care \\ Grupo de trabalho internacional para o direito aos cuidados nutricionais dos doentes
}

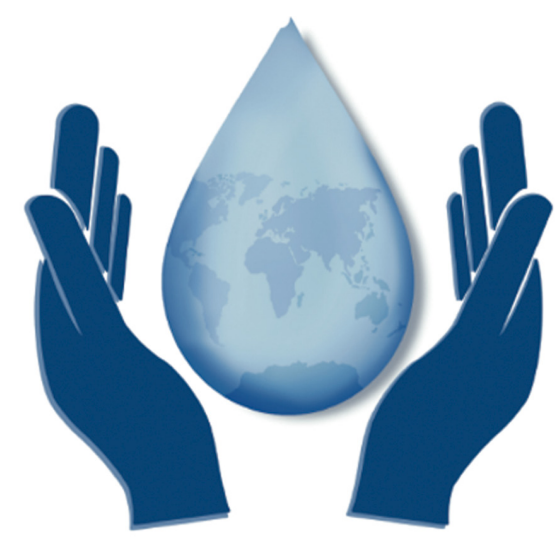

International Working Group for Patients' Right to Nutritional Care
El objetivo del grupo de trabajo internacional es estudiar el vínculo entre la nutrición clínica y los derechos humanos. El grupo promueve la defensa del acceso de todos los pacientes al cuidado nutricional a través del enfoque basado en los derechos humanos. Se trata de un nuevo enfoque en la nutrición clínica, el cual implica la colaboración interdisciplinaria entre medicina, ciencias biológicas, ciencias humanas y sociales, ciencias farmacéuticas, nutrición y dietética.

\section{Grupo de trabajo}

Dr. Juan B. Ochoa
Pr. Gil Hardy
Dr. Albert Barrocas

Expertos sin afiliación:

Pediatría

Pr. Andre Briend

Pr. Regis Hankard

Derechos humanos

Pr. Isabelle Hannequart

Historia

Pr. Loic Bienassis

Coordinador: Dr. Diana Cardenas

asPen OESPEN P FELANFE 


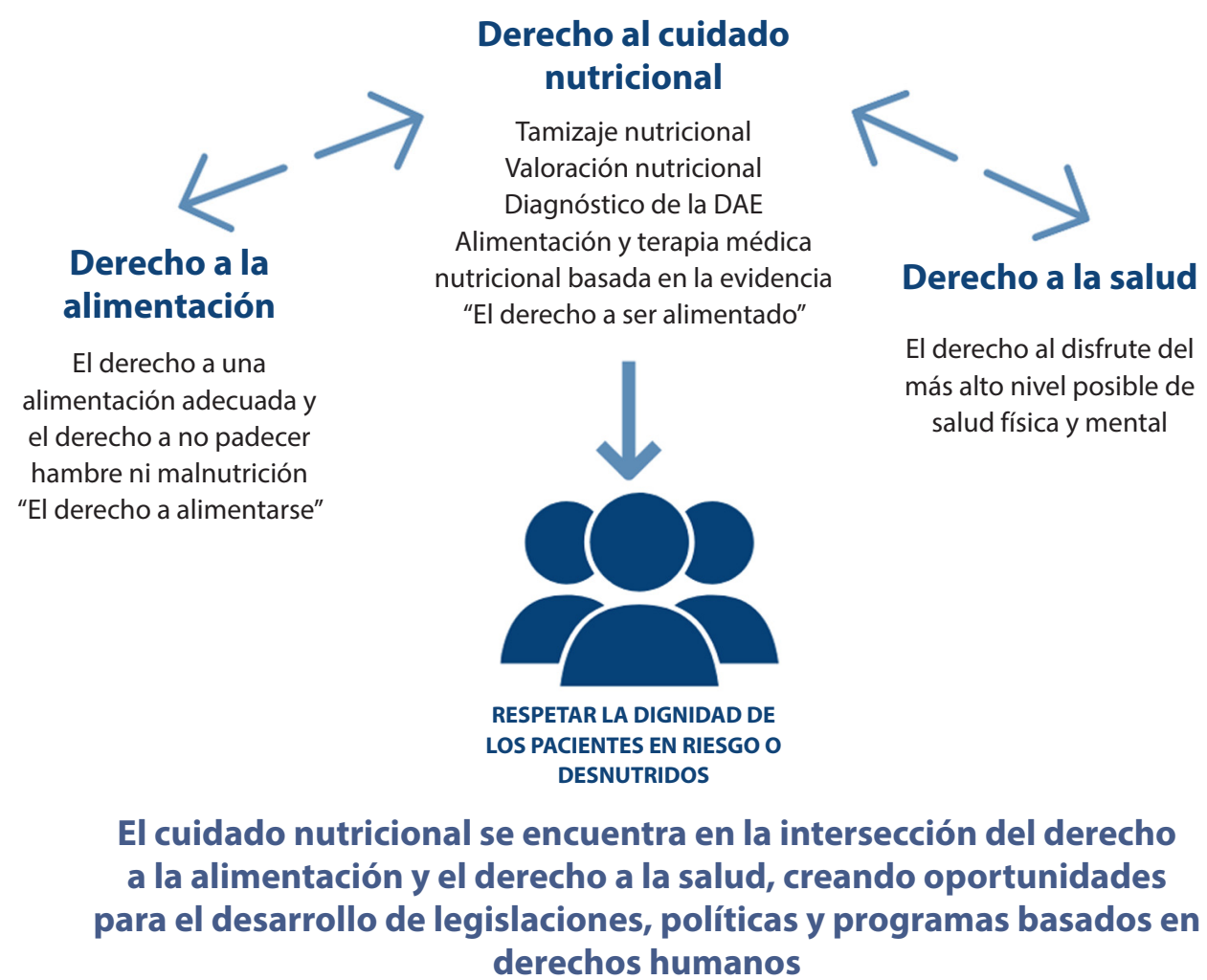

DAE: desnutrición asociada con la enfermedad

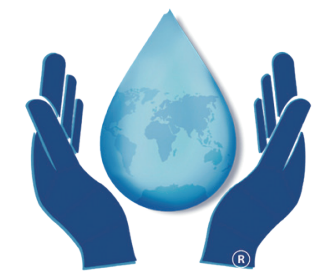

Todos los pacientes deben tener acceso al tamizaje y valoración nutricional, al diagnóstico de la desnutrición asociada a la enfermedad y a una alimentación y terapia médica nutricional basada en la evidencia.
Yo defiendo el derecho al cuidado nutricional de todos los pacientes. ¡Únete a esta campaña!

IWGHR2020@gmail.com \#CNandHR

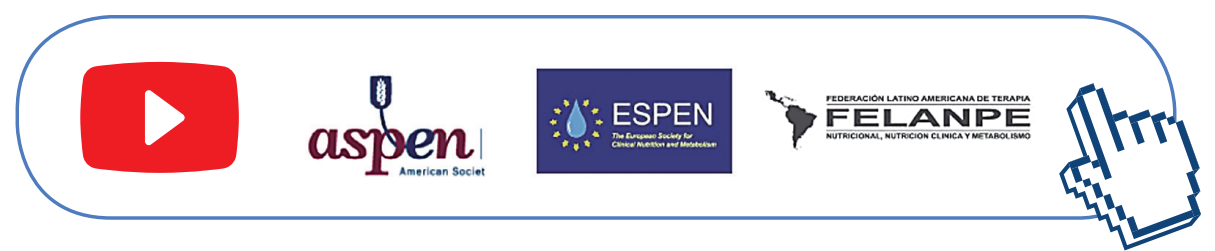

Consulte el artículo de posicionamiento: Clinical nutrition and human rights. An international position paper, disponible en:

- Cardenas D, Correia MITD, Ochoa JB, Hardy G, Rodriguez-Ventimilla D, Bermúdez CE, et al. Clinical nutrition and human rights. An international position paper. Clin Nutr. 2021;40(6):4029-4036. doi: 10.1016/j. clnu.2021.02.039 y Nutr Clin Pract 2021;36(3):534-544. 